\title{
A Historical Review of MDMA
}

\author{
Steven B. Karch*
}

Berkeley, California 94705, USA

\begin{abstract}
In less than 50 years the number of MDMA (3,4-Methylenedioxymethamphetamine or Ecstasy) users in the United States has gone from zero to nearly three million. For all of its popularity, very little is known about MDMA's probable mechanism of action, or the mechanisms by which it causes death and disability. Even less is known about this drug's checkered past, including dangerous plans by various government agencies to "weaponize" MDMA, and misleading research sponsored and propagated by the U.S. government. Recently, evidence has begun to emerge that MDMA may cause valvular heart disease and possibly myocardial disease as well. These issues have not yet appeared on the media radar. For that reason, an historical review of this fascinating drug was undertaken here.
\end{abstract}

Keywords: Ecstacy, Shulgin, history, MK-Ultra, psychoactive, serotonin, empathogen, myocardial fibrosis, neurotoxicity. MDA, Club drugs, Raves.

\section{INTRODUCTION}

Estimates of the United Nations suggest that in North America there are approximately 2.6 million MDMA (3,4Methylenedioxymethamphetamine or Ecstasy) users, mostly in the United States. The annual prevalence of MDMA use within the general U.S. population is approximately $0.9 \%$, similar to rates reported from Western and Central Europe, where 3.8 to 4.0 million MDMA users reside. Levels of MDMA use in Western and Central Europe seem to have stabilized. Similarly, most recent student surveys from the United States and Canada have shown little change in the annual prevalence of MDMA use since 2003, although the rate of use continues to increase in several Eastern and South Eastern European countries. Asia is the only area reporting significant increases. Clearly, MDMA abuse is now a worldwide phenomenon [1]. This epidemic began only 50 years ago, and its history merits attention, especially now that it is clear that MDMA users may be at considerable risk for medical harms.

Anton Kollisch (1888-1916), a German chemist, has been credited with the discovery of MDMA, but little is known about him. His employer, Merck of Darmstad, Germany obtained a patent for his creation (3,4- Methylenedioxymethamphetamine) on Christmas Eve of 1912 (Patent Number 274350). Merck named the new molecule "methylsafrylamin" [2]. Methylsafrylamin was just one of many precursor compounds synthesized by Merck in an attempt to circumvent patents held by its archrival, Bayer. Both of the pharmaceutical giants were trying to produce a drug that would promote surgical homeostasis. Bayer already held the patent on a drug called hydrastinin. Though the drug is no longer on the market, at the time it was considered the best available pro-coagulant. Urban legend has it that Merck really created MDMA as a weight loss drug. However, the rumor is simply untrue; Merck created MDMA solely for use

*Address correspondence to this author at the Berkeley, California 94705, USA; E-mail: skarch@sonic.net as a precursor compound, and never even evaluated MDMA's basic physiologic properties until years after the patent for MDMA was actually awarded.

Fifteen years passed before Merck made any effort to systematically evaluate MDMA's pharmacologic effects in animals. The first experiments were carried out in 1927. The results of these studies remain unknown. According to Freudenmann et al., the results of those particular studies can no longer be found within the Merck archives. It is likely that they were destroyed during the Allied bombing raids of World War II.

No further animal testing on MDMA was performed until 1953, when the U.S. Army undertook studies to assess the toxicity of mescaline analogues, MDMA being the bestknown member of this group. The MDMA molecule is classified as a phenethylamine, but it has strong structural similarities to both amphetamine and mescaline [3]. The Army administered MDMA to guinea pigs, rats, mice, monkeys, and dogs. The military researchers concluded MDMA was less toxic than MDA (3,4-methylenedioxyamphetamine), which, itself, was not very toxic. The Army then quickly lost interest in the subject.

Additional evidence obtained from the Merck archives suggests a man named Wolfgang Fruhstorfer (1926-) had a research interest in the production of new stimulants, and he undertook a new round of human testing in 1959. The results of his studies were never published, and there is no evidence that Merck ever followed up on Fruhstorfer initial experiments. Not long after Fruhstorfer's studies, the U.S. Army again tested, and again then lost interest, in MDMA. Army researchers had hopes that MDMA could be used in its highly classified MK-ULTRA experimental program - an exercise in mind control. These experiments began in the $1950 \mathrm{~s}$ and continued through the early 1960s. The experiments focused entirely on "weaponizing" MDMA. No true biological research was ever undertaken. When one of the program volunteers accidentally died of an overdose, the Army abandoned its efforts and destroyed many of the 
documents concerning its research program. They were not entirely successful in their efforts, and many of the reports documenting the history of this program still exist. They have recently been declassified and may be downloaded from the Web [4]. Several books based on the declassified material have also been published [5].

University and industry based medicinal chemists took up where the Army had left off and scientific human experimentation finally began in earnest. Psychiatrists suspected that MDMA had useful therapeutic properties. Much of the enthusiasm for this line of research was a result of active proselytizing by a former Dow Chemical employee Alexander Shulgin who first synthesized MDMA as an academic exercise in 1965 . He did not try the drug himself until 1967. Marie Kleinman, a graduate student in the medicinal chemistry group that Shulgin advised at San Francisco State University, finally convinced Shulgin to try the drug.

In 1976, Shulgin shared his enthusiasm about MDMA with Leo Zeff, a psychologist from Oakland, California. Zeff, who had actually been using the drug since 1961, began giving MDMA to his patients, using small doses as an aid to therapeutic interaction. Zeff proselytized actively and introduced MDMA to hundreds of psychologists around the nation, including Ann Shulgin, whom Alexander Shulgin met in 1979, and married in 1981 [6].

Shulgin, Zeff, and numerous other psychologists and psychiatrists were forcefully struck by MDMA's apparent ability to foster communication and increase empathy hence MDMA, and related drugs, came to be known as "Entactogens," or "Empathogens" [7]. There followed a series of publications in psychiatric journals. Virtually all these papers concluded that MDMA might be useful in the treatment of many unrelated problems, including hospice care and addiction treatment [8]. In many ways, the proposed uses for MDMA resembled the original claims Freud had made for cocaine [9]; namely, that it would effectively treat most of mankind's psychiatric afflictions.

U.S. federal drug regulators and college students became aware of these claims almost simultaneously. The reaction of the U.S. Drug Enforcement Agency (DEA) was to invoke its emergency powers and schedule MDMA as a Category I drug. This is the category reserved for heroin and other psychoactive drugs deemed to have extreme abuse potential, but no medical value. Congress held a series of hearings to debate the issue. Physicians arguing for the benefits of MDMA were roundly overruled by an assortment of government agency specialists who claimed correctly, it transpires that MDMA had the potential to cause brain damage. The original transcripts of these hearings have been made available on the Internet (http://www.maps.org/deamdma/\#emersched).

The Congressional hearings on MDMA received an inordinate amount of media attention. The results were as might have been expected: demand for illicit MDMA exploded and soon it was for sale on college campuses across the United States and Europe. In the United States, for yet unexplained reasons, MDMA became extremely popular in Texas and California where it soon became the recreational drug of choice [10]. To greater or lesser degrees this same trend was followed across the United States.

By the late 1980s, MDMA had also become exceedingly popular in Europe, and the "rave" (an all night dance party) was born. The phenomena seems to have begun on the Spanish island of Ibiza [11], then spreading across the Continent, and finally returning back to the United States, where Ecstasy raves drew thousands of young people. MDMA has remained popular in Europe, especially in the United Kingdom where, after alcohol and cannabis, MDMA usually rates as the third most commonly abused drug among young people.

Illicit European laboratories are the world's main suppliers of MDMA [12]. Evidence suggests that European clandestine drug makers were the first to introduce the concept of "branded" tablets that could be identified by their distinctive trademarks (see illustration below) [12-13].

European and American crime laboratories recognized early on that most confiscated MDMA tablets they analyzed had, in fact, been adulterated, and that the adulteration almost always seemed to have occurred in a systematic fashion. Initial production runs of new "branded" tablets almost always contained very high purity MDMA, and were marked with a recognizable logo appropriated from legitimate commerce ("Mitsubishi," "Mercedes," "McDonalds" see Fig. 1). Branded tablets were very popular in the mid1990s). Once brand loyalty to the logo had been established, producers would steadily lower the MDMA content of the tablet replacing it with methamphetamine (methamphetamine costs much less to synthesize than MDMA). By the mid1990s, the average MDMA tablet contained no more than 40\% MDMA [12-13]. Occasionally, other amphetamines, such as PMA (paramethoxyamphetamine), were detected, but other adulterants including aspirin, caffeine and low dosages of ephedrine were, and remain, more common. Sometime MDMA is mixed with dextromethorphan, itself a hallucinogen when abused [14]. It is still not clear whether cases of liver failure reported from Europe were the result of intentional adulteration or contamination introduced inadvertently during the manufacturing process [15]. Adulteration, intentional or otherwise, combined with the proclivity of MDMA users to simultaneously abuse other drugs, has made it very difficult to sort out the reported medical complications of MDMA use and attribute them with any surety to any specific drug.

Although the DEA had already scheduled MDMA, largely on concerns about potential toxicity, the first reports of MDMA-related deaths actually came from Europe. For the most part, these deaths were a consequence of heatrelated illness, usually associated with rhabdomyolysis [16]. However, clusters of MDMA-related hepatotoxicity, some requiring liver transplantation were reported in the early 1990s [17]. Some of the case reports described liver disease that was clearly not the result of heat induced multi-organ failure. In those cases, liver failure was likely to have been secondary to the presence of chemical contaminants introduced in the illicit-manufacturing process [18].

Few cases of MDMA-induced hepatic failure were ever reported in the United States, so it seems likely that production issues in local illicit laboratories explain the 


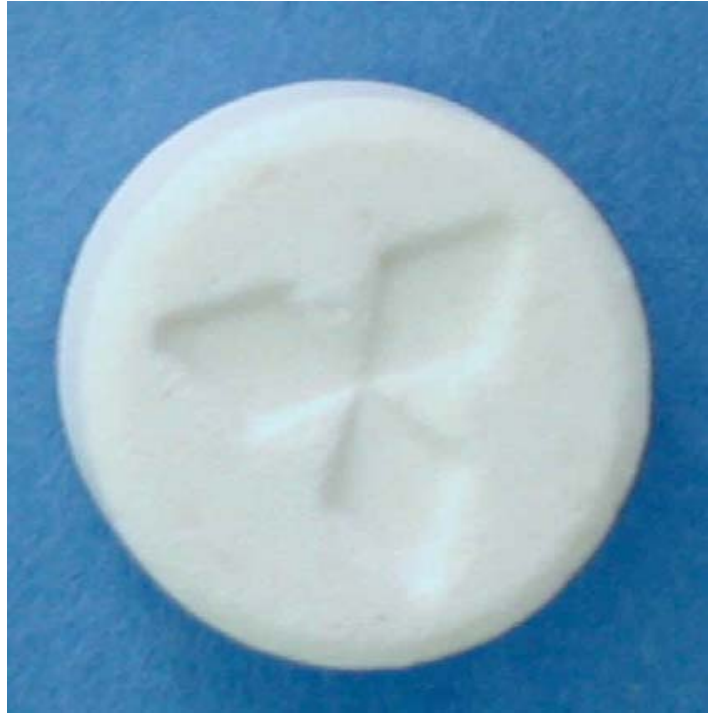

Fig. (1). Illicit MDMA Tablet Bearing The Mitsubishi Logo.

different rates of liver disease in the United States and Europe. MDMA seized in the U.S. is primarily manufactured in clandestine laboratories located in the Netherlands and Belgium. From the Netherlands, MDMA is transferred through Germany and Poland and then smuggled into the U.S. via body packers, by air/sea cargo, luggage, and even by express mail.

Recently, clandestine laboratories located in Canada, run by Asian gangs, have become important suppliers to the United States market. The U.S. Drug Enforcement Agency estimates up to one million MDMA tablets per month are smuggled into the U.S. Only a handful of small MDMA clandestine laboratories have ever been identified within the United States [19]. Surprisingly, the incidence of MDMA in other parts of the world exceeds that in the United States, particularly in the countries of Oceania. Ever since 1998, Australia and New Zealand have reported fairly striking increases in the annual prevalence of MDMA among the general population.

The DEA had justified rescheduling MDMA because of concerns over neurotoxicity. Animal researchers first raised these concerns in the late 1980s [20]. They found that when high doses of MDMA were given to rats, dramatic decreases in brain concentrations of serotonin and its metabolite, 5hydroxyindoleacetic acid were observed, although all of the animals fully recovered after one week had elapsed. Other researchers performed histological studies demonstrating damage to serotonergic neurons [21].

It was not until 1994, that conclusive evidence of MDMA neurotoxicity was reported in humans. In controlled trials, McCann found that the spinal fluid of test subjects exposed to MDMA had significantly lower levels of 5hydroxyindoleacetic acid (5-HIAA), the major serotonin metabolite, than did controls [22]. To date there have been no postmortem studies showing whether or not histological or histochemical abnormalities are evident in the bodies of chronic MDMA abusers. However, the results of noninvasive testing with functional MRI and SPECT scanning overwhelming support the notion that disruption and/or damage to the human serotonergic system does occur [23].

In September 2002, George Ricaurte, a researcher funded by the National Institute on Drug Abuse (NIDA), published the results of an experimental animal study and extrapolated the results to humans. Based on the animal results, he suggested that human MDMA users might eventually develop Parkinson's disease [24]. Ricaurte had injected a group of spider monkeys and baboons with MDMA. The animals were injected with three, $2 \mathrm{mg} / \mathrm{kg}$ doses of MDMA, each separated by three hours (in a $70 \mathrm{~kg}$ human that would be the equivalent of injecting $520 \mathrm{mg}$ of MDMA in nine hours). Ricaurte found convincing evidence of damage to dopamine-containing cells, particularly in the area of the Substantia Nigra, the area implicated in Parkinson's disease. Publication of these findings led to a flurry of media warnings that MDMA users were at risk of developing Parkinson's disease. These concerns quickly dissipated when it was discovered that Ricaurte had injected the primates with methamphetamine, a drug known to damage dopaminergic neurons, instead of MDMA. Ricaurte blamed the mix-up on the reagent maker. His paper was retracted a few months later [25]. Indirect studies of humans have never produced any data suggesting that MDMA can induce dopaminergic injury.

Revelations about Ricaurte's flawed studies were published at almost the same time that the United Nations released its own report on the growing problem of MDMA abuse. According to the UN, by 2002, yearly worldwide production of MDMA exceeded 125 tons a year. The UN also estimated eight million people worldwide were using the drug, which amounted to an increase of 70 percent over the proceeding five years.

More recently, evidence suggesting MDMA-related heart disease has begun to emerge. Most researchers had believed that MDMA spared the heart. Mounting evidence suggests that this is not the case. From the very beginning, myocardial fibrosis was a common finding in MDMA users. However, in early controlled experiments in our laboratory, statistically significant alterations were hard to demonstrate [26]. The picture is complicated by the fact that most MDMA is adulterated with methamphetamine, a drug that certainly can cause fibrosis [27]. Case reports describing MDMA-related cardiomyopathy appear sporadically, but no controlled trials, in man or animal, have ever been published. Rats exposed to high doses of MDMA do develop eccentric left ventricular dilation and diastolic dysfunction. This change is thought to be the result of oxidative stress, which leads to important changes in redox cycling, formation of superoxide MDMA metabolites, and changes in intracellular calcium transients that could ultimately result in heart failure [28], though whether these changes occur in humans is impossible to say.

Serotonergic effects on the heart are another concern. There is evidence that MDMA can cause valvular heart disease [29]. The initial association between the occurrence of valvular heart disease, and the administration of certain drugs, stems from observations made in the 1960s, when ergotamine first became widely used for migraine prophylaxis; both drugs are serotonin antagonist. That discovery was followed by the fenfluramine/dexfenfluramine disaster, and now MDMA has been implicated as a cause of 
valvular disease as well [30]. The natural history of the disease remains unclear, but the disease appears reversible.

MDMA use causes the in vitro proliferation of cardiac valvular interstitial cells, which are, in turn, activated by the 5-hydroxytryptamine-2B-receptor. When 29 subjects using, or having used, MDMA were compared with 29 gender- and age-matched controls, and then evaluated in a blinded study using echocardiography, nearly one-third of the MDMA users had abnormal echocardiographic scans (abnormal as defined by the U.S. Food and Drug Administration's criteria for appetite suppressant-induced valvular heart disease), compared with none in the control group $(p=0.0045)$ [31]. While the findings of the study are very convincing, the paucity of patients actually presenting with valvular heart disease is so low as to hardly be worth a mention. Obviously, more is involved, but this portion of MDMA's history is yet to be written.

It might be speculated that the absence of MDMA abusers with valvular disease could be explained by two facts: (1) MDMA abuse is largely confined to the young, who are inclined to abandon the practice as they age, and (2) the currently available evidence which suggests that the lesions are reversible. More data will be required before any reasonable assessment of the harms posed by MDMA can be made, but if the history of this drug tells us anything, it is simply that generalizing from animal studies and small observational studies often leads to the wrong conclusion just look at the epidemic of MDMA-related Parkinson's disease that didn't happen. At the same time, newer data proves that, even though it was never suspected, MDMA is, indeed, cardiotoxic.

\section{REFERENCES}

[1] Crime, U.N.O.o.D.a. World Drug Report, 2009; United Nations: Vienna, 2009.

[2] Freudenmann, R.W.; Oxler, F.; Bernschneider-Reif, S. The origin of MDMA (ecstasy) revisited: the true story reconstructed from the original documents. Addiction (Abingdon, England) 2006, 101 (9), 1241-1245.

[3] Smythies, J.R.; Levy, C.K. The comparative psychopharmacology of some mescaline analogues. J. Ment. Sci., 1960, 106, 531-536.

[4] Michale-Robinet DECLASSIFIED: BEYOND MK-ULTRA: THE TECHNOLOGY OF PSYCHOLOGICAL CONDITIONING IN THE 21ST CENTURY".

[5] Lee, M.; Shain, B. Acid Dreams: The Complete Social History of LSD: The CIA, the Sixties, and Beyod, Revise edition Grove Press: New York, 1994.

[6] Stolarff, M. The secret chief: conversations with a pioneer of the underground psychedelic therapy movement. The Multidisciplinary Association for Psychedelic Studies: Sarasota. FL, 1997; p 144.

[7] Shulgin, A.; Shulgin, A. Phikal. Transform Press: Berkeley, CA, 1991.

[8] (a) Grinspoon, L.; Bakalar, J.B. Can drugs be used to enhance the psychotherapeutic process? Am.J. Psychother., 1986, 40 (3), 393404.

(b) Greer, G.R.; Tolbert, R. A method of conducting therapeutic sessions with MDMA. J. Psychoactive Drugs, 1998, 30 (4), 371379.

(c) Greer, G.; Tolbert, R. Subjective reports of the effects of MDMA in a clinical setting. J. Psychoactive Drugs, 1986, 18 (4), 319-327.

[9] Freud, S. Coca, U. Wein Centralblatt fur die gest Therapie, 1884, 2, 289-314.

[10] Beck, J.; Morgan, P.A. Designer drug confusion: a focus on MDMA. J. Drug Educ., 1986, 16 (3), 287-302.
[11] Lora-Tamayo, C.; Tena, T.; Rodriguez, A.; Moreno, D.; Sancho, J.R.; Ensenat, P.; Muela, F. The designer drug situation in Ibiza. Forensic Sci. Int., 2004, 140 (2-3), 195-206.

[12] Giraudon, I.; Bello, P. Y., Monitoring ecstasy content in France: results from the National Surveillance System 1999-2004. Subst. Use Misuse, 2007, 42 (10), 1567-1578.

[13] (a) Bost, R.O. 3,4-Methylenedioxymethamphetamine (MDMA) and other amphetamine derivatives. J. Forensic Sci., 1988, 33 (2), 576-587.

(b) Milliet, Q.; Weyermann, C.; Esseiva, P. The profiling of MDMA tablets: a study of the combination of physical characteristics and organic impurities as sources of information. Forensic Sci. Int., 2009, 187 (1-3), 58-65.

(c) Fang, Y.X.; Wang, Y.B.; Shi, J.; Liu, Z. M.; Lu, L. Recent trends in drug abuse in China. Acta Pharmacol. Sin., 2006, 27 (2), 140-144.

[14] Shewan, D.; Dalgarno, P. Ecstasy and neurodegeneration. ...such as ketamine. BMJ, 1996, 313 (7054), 424.

[15] (a) Milroy, C.M.; Clark, J.C.; Forrest, A.R. Pathology of deaths associated with "ecstasy" and "eve" misuse. J. Clin. Pathol., 1996, 49 (2), 149-153. (b) Brauer, R.B.; Heidecke, C.D.; Nathrath, W.; Beckurts, K.T.; Vorwald, P.; Zilker, T.R.; Schweigart, U.; Holscher, A.H.; Siewert, J.R. Liver transplantation for the treatment of fulminant hepatic failure induced by the ingestion of ecstasy. Transpl. Int., 1997, 10 (3), 229-233.

[16] Henry, J.A. Ecstasy and the dance of death. BMJ, 1992, 305 (6844), 5-6.

[17] (a) Ellis, S.J. Complications of "ecstasy" misuse. Lancet, 1992, 340 (8821), 726.

(b) Ellis, A.J.; Wendon, J.A.; Portmann, B.; Williams, R. Acute liver damage and ecstasy ingestion. Gut, 1996, 38 (3), 454-458.

[18] Verweij, A.M. Contamination of illegal amphetamine. Hydrastatinine as a contaminant in 3,4-(methylenedioxy)methylamphetamin]. Arch. Kriminol., 1991, 188 (1-2), 54-57.

[19] National Institute on Drug Abuse, O.o.D.C. MDMA; 2005.

[20] Schmidt, C.J.; Wu, L.; Lovenberg, W. Methylenedioxymethamphetamine: a potentially neurotoxic amphetamine analogue. Eur.J. Pharmacol., 1986, 124 (1-2), 175-178.

[21] Ricaurte, G.A.; DeLanney, L.E.; Irwin, I.; Langston, J.W. Toxic effects of MDMA on central serotonergic neurons in the primate: importance of route and frequency of drug administration. Brain Res., 1988, 446 (1), 165-168.

[22] McCann, U.D.; Ridenour, A.; Shaham, Y.; Ricaurte, G.A. Serotonin neurotoxicity after (+/-)3,4-methylenedioxymethamphetamine (MDMA; "Ecstasy"): a controlled study in humans. Neuropsychopharmacology, 1994, 10 (2), 129-138.

[23] (a) de Win, M.M.; Jager, G.; Booij, J.; Reneman, L.; Schilt, T.; Lavini, C.; Olabarriaga, S.D.; den Heeten, G.J.; van den Brink, W. Sustained effects of ecstasy on the human brain: a prospective neuroimaging study in novel users. Brain, 2008, 131 (Pt 11), 29362945.

(b) Spitzer, M.; Franke, B.; Walter, H.; Buechler, J.; Wunderlich, A.P.; Schwab, M.; Kovar, K.A.; Hermle, L.; Gron, G. Enantioselective cognitive and brain activation effects of N-ethyl-3,4methylenedioxyamphetamine in humans. Neuropharmacology, 2001, 41 (2), 263-2671.

[24] Ricaurte, G.A.; Yuan, J.; Hatzidimitriou, G.; Cord, B.J.; McCann, U.D. Severe dopaminergic neurotoxicity in primates after a common recreational dose regimen of MDMA ("ecstasy"). Science, 2002, 297 (5590), 2260-2263.

[25] Ricaurte, G.A.; Yuan, J.; Hatzidimitriou, G.; Cord, B.J.; McCann, U.D. Retraction. Science, 2003, 301 (5639), 1479.

[26] Milroy, C.; Fornes, P.; Karch, S. Personal Communication. 1998.

[27] Karch, S.B.; Stephens, B.G.; Ho, C.H. Methamphetamine-related deaths in San Francisco: demographic, pathologic, and toxicologic profiles. J. Forensic Sci., 1999, 44 (2), 359-368.

[28] Shenouda, S.K.; Varner, K.J.; Carvalho, F.; Lucchesi, P.A. Metabolites of MDMA induce oxidative stress and contractile dysfunction in adult rat left ventricular myocytes. Cardiovasc. Toxicol., 2009, 9 (1), 30-38.

[29] Setola, V.; Hufeisen, S.J.; Grande-Allen, K.J.; Vesely, I.; Glennon, R.A.; Blough, B.; Rothman, R.B.; Roth, B.L. 3,4methylenedioxymethamphetamine (MDMA, "Ecstasy") induces fenfluramine-like proliferative actions on human cardiac valvular interstitial cells in vitro. Mol. Pharmacol., 2003, 63 (6), 1223-1229. 
[30] Bhattacharyya, S.; Schapira, A.H.; Mikhailidis, D.P.; Davar, J. Drug-induced fibrotic valvular heart disease. Lancet, 2009, 374 (9689), 577-585.

[31] Droogmans, S.; Cosyns, B.; D'Haenen, H.; Creeten, E.; Weytjens, C.; Franken, P.R.; Scott, B.; Schoors, D.; Kemdem, A.; Close, L.;
Vandenbossche, J.L.; Bechet, S.; Van Camp, G. Possible association between 3,4-methylenedioxymethamphetamine abuse and valvular heart disease. Am. J. Cardiol., 2007, 100 (9), 14421446.

(C) Steven B. Karch; Licensee Bentham Open.

This is an open access article licensed under the terms of the Creative Commons Attribution Non-Commercial License (http://creativecommons.org/licenses/by-nc/3.0/) which permits unrestricted, non-commercial use, distribution and reproduction in any medium, provided the work is properly cited. 